\title{
A ARTICULAÇÃO DO TEXTO ARGUMENTATIVO ORAL
}

Iara Bemquerer Costa*

\section{Introdução}

$\mathrm{E}$

$\mathrm{m}$ trabalho anterior (Costa e Godoy, 1997) analisamos um pequeno conjunto de textos argumentativos recolhidos de entrevistas orais não planejadas, a partir dos quais fizemos uma caracterização preliminar das formas de construção argumentativa encontradas. Os resultados daquele estudo serviram de ponto de partida para a análise de um corpus mais amplo, que ora apresentamos. $O$ estudo da argumentação no texto oral não planejado é particularmente interessante, pois pode revelar as matrizes mais elementares da organização argumentativa do discurso. Sua análise pode ajudar no reconhecimento das características nucleares desse gênero discursivo, que também estarão presentes, em maior ou menor grau, nos discursos argumentativos produzidos em contextos institucionalizados, em que a argumentação se faz mediante o uso de técnicas mais elaboradas.

Há, certamente, entre as duas situações, diferenças significativas, uma vez que os discursos políticos ou jurídicos sofreram, ao longo do tempo, um processo histórico de elaboração da sua forma, que resultou na fixação de técnicas argumentativas mais elaboradas, usadas de forma recorrente no interior das instituições em que tais discursos são produzidos, especialmente quando os falantes produzem seus enunciados a partir de lugares institucionais bem definidos. ${ }^{1}$ De

* Universidade Federal do Paraná - CNPq (Processo 301279/95-0).

1 Assumimos o conceito de "lugares institucionais" formulado por Pêcheux (1993, p. 82): "algo diferente da presença física de organismos humanos individuais"; "lugares determinados na estrutura de uma formação social, lugares dos quais a sociologia pode descrever o feixe de traços objetivos característicos". 
forma diversa do que se observa nos discursos constituídos em instâncias públicas, ${ }^{2}$ o discurso argumentativo registrado numa conversação informal tem a peculiaridade de ser dirigido a um só interlocutor em uma instância de comunicação que, embora não possa ser caracterizada como privada, uma vez que a presença do gravador lembra ao falante que sua fala poderá atingir um número maior de interlocutores do que o entrevistador que está diante dele, não tem as características de uma argumentação realizada no interior de uma instituição e dirigida a um conjunto maior de interlocutores.

As seqüências argumentativas produzidas durante entrevistas orais não planejadas constituem o material empírico a partir do qual fizemos a presente análise. Ao observar os dados, procuramos nos concentrar em duas questões. Em primeiro lugar, examinamos a argumentação presente nos textos tendo como referencial as categorias analíticas adotadas pela retórica moderna para estudo da argumentação em suas diversas manifestações, segundo Perelman e Olbrechts-Tyteka (1996). Queremos observar, nos recortes de entrevistas, os aspectos reconhecidos pela retórica como fundamentais para a constituição de textos argumentativos produzidos em circunstâncias diversas: a presença de indícios de um auditório, ou seja, do conjunto de indivíduos que o autor pretende influenciar com seus argumentos; a identificação dos acordos prévios subjacentes à argumentação, ou seja, do conjunto de fatos, verdades, valores e hierarquias presumivelmente compartilhados pelo autor e seu auditório; o recurso a um conjunto de técnicas argumentativas, de formas de articulação das evidências mobilizadas para a sustentação do ponto de vista defendido. Todos esses aspectos, caracterizados pela retórica nos textos argumentativos mais complexos, produzidos em instâncias políticas, jurídicas, científicas etc., devem também ser encontrados na fala espontânea, certamente em formatos particulares.

Procuramos também, num segundo momento, examinar as marcas formais da articulação textual encontradas de forma recorrente nas sequiências argumentativas selecionadas nas entrevistas gravadas, procurando verificar as escolhas formais relativas à introdução da tese e dos argumentos e a sua organização sequiencial.

Para o presente estudo, selecionamos textos produzidos por falantes de diversos níveis de escolaridade, tanto aqueles com escolarização formal limitada a quatro anos quanto os que concluíram curso superior. Os textos analisados foram retirados do Banco de Dados Lingüísticos Varsul (Variação Lingüística Urbana na Região Sul). Trata-se de um corpus com entrevistas controladas

2 Sobre a questão dos usos discursivos em instâncias públicas e privadas, ver Geraldi (1996), p. $39-45$. 
sociolingüisticamente, composto por 32 entrevistas gravadas na cidade de Curitiba, com falantes de ambos os sexos, de duas faixas etárias ( 25 a 50 anos; mais de 50 anos), e de 4 níveis de escolaridade (primário - até 5 anos de permanência na escola; ginásio - até 9 anos; segundo grau - até 11 anos; superior - curso concluído).

Em cada entrevista, procuramos fazer inicialmente o recorte das seqüências que puderam ser identificadas como textos argumentativos. A seguir analisamos as características recorrentes nos trechos selecionados, mas não tivemos a preocupação de fazer uma análise quantitativa desse material. Assim, os resultados que ora apresentamos contemplam as caracteristicas recorrentes observadas nas 32 entrevistas analisadas, ainda que, para fins de exposição, sejam sempre selecionados textos exemplares para evidenciar cada um dos aspectos que pretendemos comentar.

Para o recorte dos textos argumentativos ao longo das entrevistas, foi necessário, inicialmente, dar conta de uma questão prévia: como delimitar, no fluxo de uma entrevista oral dialogada, o início e o final dos textos argumentativos a serem analisados? Procuramos estabelecer critérios que se adequassem às indicações de Bakhtin para a identificação dos enunciados enquanto unidades de interação claramente reconhecíveis.

As fronteiras do enunciado concreto, compreendido como uma unidade de comunicação verbal, são determinados pela alternância dos sujeitos falantes, ou seja, pela alternância dos interlocutores. Todo enunciado - desde a breve réplica (monolexemática) até o romance ou o tratado científico comporta um começo absoluto e um fim absoluto: antes de seu início, há os enunciados dos outros, depois de seu fim, há os enunciados-respostas dos outros (ainda que seja como uma compreensão responsiva ativa muda ou como um ato-resposta baseado em determinada compreensão). (Bakhtin, 1992, p. 293294. Grifos do autor)

Assim, o primeiro critério para efetuar o recorte no fluxo da entrevista é a tomada do turno pelo falante, mais especificamente, o momento em que o entrevistador propõe uma questão a seu interlocutor e este se dispõe a emitir uma opinião a respeito e a justificá-la. De forma análoga, o final do texto é marcado, usualmente, pela volta da palavra ao entrevistador, o qual se manifesta frente à sequiência emitida por seu interlocutor, mediante a emissão de "enunciadosrespostas", usualmente comentários, à sequeência argumentativa produzida ou marca o final do tópico mediante a introdução de um novo tema na entrevista. Observamos, 
no entanto, que nem sempre a ocorrência de uma intervenção do entrevistador marca o fim do texto. Muitas vezes as intervenções são enunciados colaborativos, que assinalam o interesse pela fala do outro, bem como ajudam o falante na escolha das formas para dizer aquilo que pretende. Assim, o recorte dos textos argumentativos ao longo das entrevistas examinadas não foi feito de forma automática, tomando certos indícios como definidores do início e fim do texto, mas a partir de uma interpretação de cada seqüência. $O$ recorte de unidades textuais no fluxo da entrevista depende, por um lado de marcas formais, em especial a mudança de turno, por outro, da interpretação do que as mudanças de turno representam, se introduzem enunciados colaborativos na construção discursiva ou se têm o caráter de reorientação do tópico discursivo, com a introdução de novos temas para a continuidade da conversação.

Feita a seleção das seqüências a serem analisadas, procuramos identificar as características recorrentes no conjunto de textos. Para fins de exposição, escolhemos textos em que estejam presentes as características encontradas de forma recorrente no corpus.

\section{A organização argumentativa do texto oral}

O discurso argumentativo oral não planejado: a manifestação mais simples de um gênero?

Os estudos recentes do texto revelam um interesse cada vez mais acentuado por questões relacionadas à diferenciação entre os diversos gêneros. A busca da identificação das características definidoras do texto em geral tem sido complementada por um interesse em identificar as características peculiares de cada tipo de manifestação textual. Nesse contexto, o trabalho de Bakhtin (1992) tem inspirado estudos que procuram ultrapassar classificações tradicionais dos textos como poesia e prosa; narração, descrição e dissertação; épico, lírico e dramático. Para ele, em qualquer manifestação discursiva podemos perceber uma diferenciação de gêneros: "Para falar, utilizamo-nos sempre dos gêneros do discurso, em outras palavras, todos os nossos enunciados dispõem de uma forma padrão e relativamente estável de estruturação de um todo." (Bakhtim, 1992, p. 301).

Ao fornecer as diretrizes para uma análise dos gêneros discursivos, Bakhtin aponta para o reconhecimento de uma diversidade crescente de gêneros discursivos, associados à diferenciação e estabilização de usos da linguagem dentro de sociedades complexas: "Uma dada função (científica, técnica, ideológica, oficial, 
cotidiana) e dadas condições específicas para cada uma das esferas da comunicação verbal, geram um dado gênero, ou seja, um dado tipo de enunciado, relativamente estável do ponto de vista temático, composicional e estilístico." (Bakhtim, 1992, 284)

A questão dos gêneros discursivos não se coloca apenas para as formas discursivas já estabilizadas na escrita, ou que foram objeto de estudo na teoria da literatura, retórica ou gramática. Pelo contrário, é na conversação usual que se encontram as manifestações fundadoras da diversidade dos gêneros. Assim, ao definir como objeto deste estudo a argumentação presente em entrevistas orais não planejadas, achamos relevante destacar a relação que Bakhtin aponta entre essa forma simples do gênero argumentativo e as formas mais complexas, que são objeto de estudo desde a antiguiidade, a partir da Arte Retórica de Aristóteles.

Importa, nesse ponto, levar em consideração a diferença essencial existente entre o gênero de discurso primário (simples) e o gênero de discurso secundário (complexo). [...]

Os gêneros secundários do discurso - o romance, o teatro, o discurso científico, o discurso ideológico etc. - aparecem em circunstâncias de uma comunicação cultural, mais complexa $e$ relativamente mais evoluída, principalmente escrita: artística, científica, sociopolítica. Durante o processo de sua formação, esses gêneros absorvem e transmutam os gêneros primários (simples) de todas as espécies, que se constituíram em circunstâncias de uma comunicação verbal espontânea. (Bakhtin, 1992, p. 281. Grifos do autor)

Se Bakhtin estiver certo na relação histórica que estabelece entre os gêneros discursivos que ele designa como primários (simples) e secundários (complexos), os dados que tomamos como objeto deste estudo - textos argumentativos produzidos durante entrevistas informais - podem nos dar indicações sobre as matrizes elementares da argumentação, que, usadas em instituições diversas, associadas à escrita e a usos normatizados ao longo de séculos, vieram dar origem aos discursos argumentativos institucionalizados e complexos, que são tradicionalmente estudados pela retórica: o discurso político, a argumentaçāo jurídica e, mais recentemente, o texto publicitário.

Assim, esperamos encontrar nessas formas mais simples de construção argumentativa algumas características apontadas pela retórica como definidoras do gênero argumentativo em suas formas mais elaboradas. Se o discurso argumentativo 
institucionalizado nos autos jurídicos, nas intervenções de políticos no parlamento, nos estudos científicos é o resultado de uma estabilização institucionalizada de um gênero discursivo que tem suas manifestações mais simples no diálogo informal, é possível examinar as manifestações orais não planejadas com o uso do mesmo instrumental teórico sistematizado a partir da análise de usos variados e complexos do discurso argumentativo.

\section{A macro-estrutura do texto argumentativo oral}

Para a análise dos textos selecionados no Banco de Dados Varsul, vamos primeiramente buscar identificar os elementos que Perelman e Olbrechts-Tyteka (1996) propõem como característicos de todo tipo de argumentação. É importante apontar que estamos adotando o conceito de macro-estrutura usado por Van Dijk (1992, p. 22) para referir-se à organização do texto em torno de um tema geral.

Ao formularem uma teoria da argumentação, Perelman e Olbrechts-Tyteka explicitam que "o objeto dessa teoria é o estudo das técnicas discursivas que permitem provocar ou aumentar a adesão dos espiritos às teses que se lhes apresentam ao assentimento" (p. 4, grifo dos autores). Algumas questões prévias se colocam para a formulação de uma teoria da argumentação. Primeiramente, é necessário levar em conta que a adesão do interlocutor tem intensidade variável. Daí a necessidade de se estabelecer uma distinção entre os raciocínios e procedimentos relativos à argumentação, associados à promoção ou aumento da adesão a uma tese, daqueles relativos à demonstração e à dedução. Nestas, procuramos chegar a evidências absolutas, através da apresentação de provas, que devem demonstrar determinadas proposições de forma cabal, de modo a levar qualquer ser racional a aceitá-las; em contraposição, os procedimentos relativos à argumentação operam com graus variáveis de adesão a uma tese. Grupos diferenciados de falantes podem ser convencidos em graus diferentes por uma dada argumentação. No estudo da argumentação, não está em questão nem o convencimento de todos os interlocutores, nem sua adesão absoluta às teses que lhes são apresentadas. Ao contrário da demonstração lógica, consideramos na argumentação a possibilidade de adesão/rejeição parcial.

Em segundo lugar, não podemos esquecer que as técnicas são selecionadas pelo falante levando em conta, primeiramente, seu interlocutor, ou, nos termos de Perelman e Olbrechts-Tyteca, seu auditório, definido como "o conjunto daqueles que o orador quer influenciar com sua argumentação" (p. 22). Para esses autores, 
o auditório tem uma importância tão grande na argumentação que se superpõe aos valores assumidos pelo próprio autor: "o importante, na argumentação, não é saber o que o próprio orador considera verdadeiro ou probatório, mas qual é o parecer daqueles a quem ela se dirige". (p. 26) O falante define seus procedimentos argumentativos a partir de uma representação, uma imagem do seu interlocutor, que pode ser (ou não) construída com base no conhecimento real do grupo particular de indivíduos que fazem parte do seu auditório. $O$ conceito de representação do auditório apresenta grande afinidade com a proposta de jogo de imagens de Pêcheux (1993, p. 82-83), que usa esse conceito para mostrar que a construção do discurso é influenciada pelo conjunto de formações imaginárias (representações) que o falante tem do lugar que ele próprio ocupa na formação social, do lugar do interlocutor e das representações que um e outro têm dos referentes de que falam.

Buscando uma aproximação entre Pêcheux e a Retórica Moderna, é possivel afirmar que faz parte da representação do auditório a pressuposição de que os interlocutores compartilham a aceitação de um conjunto de premissas implícitas, que são admitidas como um acordo prévio, sobre o qual toda a argumentação é construída. Esse acordo contempla o compartilhamento de um conjunto de fatos, verdades, hierarquias, valores, presunções, os quais são aceitos por grupos de extensão variável. Uma verdade como "a terra é redonda" é partilhada por um grupo de falantes bem mais amplo do que "a Reitoria da Universidade Federal do Paraná está situada na Rua XV de Novembro". Enquanto o acordo em relaçāo à primeira proposição pode ser presumido na argumentação voltada a um auditório universal, a segunda só pode ser usada na argumentação voltada a um grupo restrito de interlocutores, ou, nos termos de Perelman e Olbrechts-Tyteca, a um auditório particular. Os objetos de acordo, que permanecem quase sempre implícitos, sustentam em grande parte a argumentação.

\section{Operando com os conceitos da retórica moderna para o estudo da oralidade}

Nos textos analisados nesse trabalho, temos, em geral, a argumentação voltada a um interlocutor único, o entrevistador ou, quando muito, a dois interlocutores, nos casos em que a entrevista contou com a participação ou de um segundo entrevistador ou de um membro da família do entrevistado. Esse auditório reduzido tem, certamente, conseqüências na elaboração das seqüências argumentativas por parte do falante. Os entrevistadores foram, em geral, alunos 
do Curso de Letras da UFPR, em geral mais jovens e com nível de escolaridade mais alto que os entrevistados. $O$ auditório ao qual se dirige a argumentação está muito bem delimitado nesse corpus. Como se trata de entrevistas face a face, o falante tem acesso constante às atitudes do seu interlocutor, que mostra sua reação aos argumentos apresentados através de expressões de concordância ou dúvida. Como as entrevistas foram conduzidas a partir das técnicas desenvolvidas pela sociolinguística variacionista, o entrevistador foi orientado a fazer o mínimo de intervenções possíveis no fluxo verbal do entrevistado. Assim, em geral ele se furta de manifestar a discordância, uma vez que tem como objetivo deixar o falante manifestar-se com a maior liberdade possivel.

Para uma primeira aproximação ao uso dos conceitos da retórica para a análise da argumentação oral não planejada, tomemos um texto, produzido por um falante com escolarização primária, que apresenta características recorrentes no material analisado. ${ }^{3}$

\section{Texto 1}

E - Que que você acha (hes) da religião hoje, (hes) não igreja, né? religião mesmo e coisa, e até de surgimento de várias congregações?

F- É um baita de um comércio, né? É um comércio que... eu acho

3 Nas citaçōes de dados extraídos do Banco de Dados Varsul, mantivemos as seguintes notações usadas nas transcrições originais, conforme KNIES e COSTA (1996):

1) Os participantes das entrevistas foram identificados como $E$, entrevistador, F, falante $\mathbf{e}$, interveniente;

2) Foram mantidas entre parênteses as observações do transcritor sobre informações não linguísticas relevantes para a compreensāo do fluxo da conversação, entre as quais destacamos: (est) estímulo do entrevistador mediante a produção de sons que geralmente não constituem palavras e são reveladores de atenção e concordância em relação ao que o falante afirma; (hes) hesitação; (risos E, F, I ou risos geral) risos de um ou todos os participantes da situação; (inint), trecho ininteligível, cuja transcrição não pôde ser feita; ruídos que interferem no fluxo da entrevista, como campainha, telefone, latidos;

3) Usamos a transcrição de primeira linha do Banco de Dados, que contém a sintaxe real do falante, mas não traz informações fonéticas nem a concordância nominal e verbal efetivamente usadas;

4) A pontuação adotada aproxima-se, na medida do possível, da escrita.

5) As entrevistas são identificadas, no final, mediante os mesmos recursos usados na sua identificação no Banco de Dados: a indicação do Estado do Paraná (PR), da cidade de Curitiba (CTB), do número da entrevista e das linhas correspondentes ao trecho citado no arquivo eletrônico. 
que é um dos melhores, né? porque todas as igrejas que surgem, religião nova, todo mundo fica rico, né? Que gozado que é, né? E surge uma ali, já se compra um... um terreno lá em cima, já faz outra, então hoje já não existe mais religião, existe o comércio, então como está desacreditada a religião. $O$ cara quer saber se foi pago tudo, dali a pouco vem a sacolinha, então eles querem dinheiro, eles não querem pregar a palavra de... Eu sei lá, eu acho que (hes) a religião você tem que... em casa você faz tua oração lá, se você acredita em Deus ou não acredita. (latidos) Ontem mesmo fiquei assistindo o Jornal Nacional lá, que o bispo lá falou que era (inint) (latidos), não sei o quê e roubou dinheiro da igreja, então quer dizer... isso aí cada vez mais se faz (inint).

$\mathrm{E}$ - O que que você acha assim que... que contribui pra... (inint) (latidos)

F - A... a carência do povo... a carência do povo, (hes) o baixo salário, então hoje o... a pessoa está confiando em tudo, então ela confia, ela acha que ali ela vai ser melhor e... e começa a frequientar e é aquilo ali, eu acho que a cabeça do povo hoje está muito fraca, (ruído) cada vez está fraquejando mais, então ela passa a acreditar em tudo que vê e tudo que... E... e é o lado errado, e é onde ela está enchendo um montão de gente de dinheiro e... e não leva a nada a ele, né? (est) Porque você veja bem uma coisa, a pessoa... o cara é... Vamos analisar agora friamente. (est) $\mathrm{O}$ cara é... ele... ele trabalha, ele vai ali no bar, bebe a pinguinha dele, chega em casa, compra a carne dele e...e compra mais uma garrafa de pinga, então tá. Daí ele vira crente. (est) Então ele diz que a vida dele melhorou. Melhorou por quê? Melhorou porque... da seguinte maneira: ele parou de ir naquele bar e comprar aquela cachaça, parou de fumar, parou de ir no jogo, então vai sobrar, então tem que melhorar a vida, mas não é porque ele está na igreja. Ele não precisa ir lá na igreja dos crentes, ele pode fazer isso sem ir na igreja que melhora igual, entendeu? Que dai eles atribuem que foi a igreja e dai eles vão... eles são... eles vão ainda ajudar a igreja. É, igreja nada! Que ele que se ajudou sozinho, mas não precisava ele ir lá, entendeu? Eu acho que a igreja só é um comércio, é um dos maiores comércios que existem hoje, né? no mundo é a igreja. (est) Tanto católica, como crente, como qualquer uma.

E - E da... da visita do Papa o ano passado, o que que você acha? (PRCTB07 - Linhas 1314 a 1376) 
Ao observarmos esse texto a partir dos conceitos da retórica, constatamos, inicialmente, que cabe ao auditório (entrevistador) o papel de propor o tema sobre o qual quer a manifestação do ponto de vista do falante. Ao contrário da argumentação em instâncias públicas, como reuniões e assembléias, em que o falante tem que garantir o direito à palavra para expor seu ponto de vista, na entrevista oral o entrevistador não só lhe garante a palavra como cria a obrigação de que faça uso dela, já que lhe faz uma pergunta direta. Nas entrevistas orais não planejadas com as quais trabalhamos, o auditório tem o papel de direcionar a sequiência temática da entrevista. Assim, o falante organiza sua argumentação não porque assume ativamente o papel de convencer o interlocutor a aderir a uma determinada tese, mas como resposta a uma proposição desse interlocutor. No caso citado, como na maior parte do corpus analisado, o entrevistador se apresenta como alguém de nível de escolaridade superior ao entrevistado, o que certamente influencia a forma de organização do texto opinativo que este enuncia. Enquanto entrevistador fisicamente presente diante do entrevistado, ele fornece elementos para a constituição de uma imagem que, certamente, não resulta apenas de suas características perceptíveis pelo entrevistado, leva em conta também com uma representação de estudante universitário construída social e historicamente pelo falante.

Nesse texto sobre religião, podemos identificar alguns objetos de acordo, que são um conjunto de valores associados ao que seria uma religião autêntica: voltada para a divulgação da palavra de Deus e sem a preocupação com bens materiais. Esse conceito de religião autêntica, verdadeira, que o falante supõe ser compartilhado pelo entrevistador, fica implícito em toda sua construção argumentativa.

Observando mais diretamente como o falante elabora seu discurso, notamos que ele inicia pela apresentação de sua tese, que aparece com uma primeira formulação no início do texto (é um baita de um comércio) e ganha uma forma mais completa logo adiante: hoje já não existe mais religião, existe o comércio, então, como está desacreditada a religião. A sustentação dessa opinião se faz a partir da seguinte organização argumentativa. Primciramente, o falante faz uma generalização, certamente infundada e apressada: porque todas as igrejas que surgem, religião nova, todo mundo fica rico, né? Pela formulação dessa proposição, ela se aproxima do argumento pelo vínculo causal (Perelman e Tyteka p. 308): ao reunir duas afirmações - o surgimento de igrejas novas e o enriquecimento das pessoas que atuam nelas - o falante aponta uma relação de causalidade entre os dois fatos: as pessoas enriquecem por causa da sua atuação na igreja.

A seguir, apresenta ilustrações, elaboradas a partir de exemplos fictícios, 
que servem para reforçar seu ponto de vista: E surge uma ali, já se compra um... um terreno lá em cima, já faz outra; dali a pouco vem a sacolinha, então eles querem dinheiro. Na organização argumentativa do texto, esses exemplos, por sua relação com a formulação da tese, têm o caráter de ilustrações. Segundo Perelman e Tyteka (1996, p. 407):

\begin{abstract}
A ilustração difere do exemplo em razão do estatuto da regra que uma e outro servem para apoiar. Enquanto o exemplo era incumbido de fundamentar a regra, a ilustração tem a função de reforçar a adesão a uma regra conhecida e aceita, fornecendo casos particulares que esclarecem o enunciado geral, mostram 0 interesse deste através da variedade de aplicações possíveis, aumentam-lhe a presença na consciência.
\end{abstract}

Na sequiência, o falante trabalha com um exemplo real, reforçado pela referência à fonte, que tem na construção argumentativa o papel de ilustração: Ontem mesmo fiquei assistindo o Jornal Nacional lá, que o bispo lá falou que era (inint) (latidos), não sei o que e roubou dinheiro da igreja, então quer dizer, isso ai cada vez mais se faz (inint).

Recorre mais uma vez à ilustração, como uma forma de reforço a sua opinião sobre as religiões, e apresenta o caso fictício da pessoa que atribui a melhora em sua vida à religião. Usa o exemplo para mostrar que é possível dar outra interpretação ao mesmo caso, em que se relaciona a melhora na vida da personagem se deve ao fato de ter abandonado a bebida e não a sua conversão.

Finalmente, o falante encerra sua argumentação de forma bem parecida com o que se vê usualmente em textos de opinião escritos, com a retomada da tese de forma contundente, uma vez que já ocorreu sua "comprovação" por meio do conjunto de evidências apresentadas: Eu acho que a igreja só é um comércio, é um dos maiores comércios que existe hoje, né? no mundo é a igreja. (est) Tanto católica, como crente, como qualquer uma.

O comentário sobre a organização argumentativa do texto 1 mostra que um texto oral não planejado, produzido a partir de um tema proposto durante uma entrevista, apresenta semelhanças significativas com a organização de textos de opinião escritos, produzidos a partir de uma elaboração bem mais sofisticada e publicados em veículos de circulação ampla. 


\section{As técnicas argumentativas}

Uma das questões relevantes ao analisarmos a organização argumentativa na oralidade é a identificação das técnicas usadas de forma recorrente. Os esquemas argumentativos empregados nesses textos indicam quais as técnicas mais elementares, mais prontamente acessíveis aos falantes. Essas técnicas, em versões mais elaboradas, devem estar presentes também nas formas de argumentação utilizadas nos discursos produzidos em esferas públicas.

O exame dos textos argumentativos retirados das entrevistas orais mostra que a construção argumentativa típica desse tipo de texto está centrada no que Perelman e Olbrechts-Tyteca (1996, p. 399) classificam como fundamento pelo caso particular. Para o falante, na conversação usual, basta apresentar fatos de sua experiência pessoal, casos divulgados na mídia, ou exemplos fictícios para assumir que sua tese está devidamente respaldada pela apresentação de argumentos. $\mathrm{O}$ uso do caso particular como argumento para a sustentação de pontos de vista na argumentação é comentado por Perelman e Olbrechts-Tyteca, que mostram as formas desses argumentos, e apontam seus limites na construção argumentativa. Segundo esses autores, "Este (o recurso ao caso particular) pode desempenhar papéis muito variados: como exemplo, permitirá uma generalização; como ilustração, esteará uma regularidade já estabelecida; como modelo, incentivará a imitação." (p. 299)

A imensa maioria dos argumentos encontrados nas entrevistas orais gravadas pode ser classificada, a partir dos critérios de Perelman e Olbrechts-Tyteca, como exemplos ou ilustrações: os casos particulares são apresentados para fundamentar uma generalização, ou para reforçar uma generalização feita. Observamos, é claro, vários casos de generalizações apressadas e infundadas, que poderiam ser facilmente refutadas a partir de sua contraposição a outros exemplos. Mas a questão que nos colocamos neste estudo não é a avaliação da consistência da argumentação encontrada nas entrevistas orais, mas a observação de suas características, seja no plano de sua organização argumentativa, seja no conjunto de recursos formais usados.

Assim, ao observarmos o uso de exemplos, é interessante ter em mente algumas observações feitas por Perelman e Olbrechts-Tyteca quanto ao uso desse tipo de argumento. Eles apontam, primeiramente, a necessidade de que aquilo que seja apresentado como exemplo tenha o caráter de ser um fato: "Seja qual for a maneira pela qual o exemplo é apresentado, em qualquer área que se desenvolva a argumentação, o exemplo invocado deverá, para ser tomado como tal, usufruir estatuto de fato, pelo menos provisoriamente; a grande vantagem de sua utilização é dirigir a atenção a esse estatuto." (p. 402) 
Outra questão pertinente a ser observada é a relação que os exemplos apresentados no curso de uma dada argumentação mantêm entre si e com o princípio geral que procuram fundamentar:

Qual é a generalização que pode ser tirada do exemplo? A essa questão se vincula estreitamente a de saber quais são os casos que podem ser considerados exemplos da mesma regra. Isso porque é em relação a uma certa regra que alguns fenômenos são intercambiáveis e, por outro lado, a enumeração destes permite discernir o ponto de vista no qual foram assimilados um ao outro. (p. 403)

No corpus de textos argumentativos selecionados para o presente estudo, não observamos uma diferença significativa na seleção das técnicas usadas para fundamentar o ponto de vista entre os falantes de níveis de escolaridade diversos. Percebemos, nos textos dos falantes com formação universitária, um maior detalhamento na apresentação dos exemplos e ilustrações e o recurso a um número maior de casos particulares para a fundamentação de suas teses. Há uma diferença que não se dá na escolha das técnicas, mas em seu uso, o que podemos perceber na comparação entre o texto 2, analisado a seguir, e o texto 1. Podemos, portanto, afirmar que esses textos apontam para uma seleção de técnicas características do gênero de discurso escolhido: produzido em uma instância privada, na modalidade oral, não planejado previamente. As diferenças observadas entre os falantes de níveis diversos de escolaridade não afetam a construção textual nesse aspecto particular: a escolha das técnicas mediante as quais o falante argumenta em defesa do seu ponto de vista.

O texto que se segue é parte da entrevista de um falante formado em Letras, que trabalha como técnico na manutenção de equipamentos em uma refinaria da Petrobrás. Para formular sua tese de que há necessidade de informatização da refinaria, em vista da globalização da economia e de uma possível privatização da empresa, ele parte da apresentação do exemplo da relação entre o quadro de funcionários e o nível de produtividade dentro da empresa.

Texto 2

E - E desde quando você entrou você trabalha com a mesma coisa.

F - Com a mesma coisa. É... agora já é um pouquinho mais burocrático, né?, você já tem... já estou em grau de supervisão, 
né? aquela coisa toda, né? Tem toda uma escala lá pra subir, né? E - Sei.

F - Então hoje tem uma equipe que chefia, mas é a mesma coisa.

Só que o equipamento é cem por cento outro quase.

E - É, porque hoje acredito que seja tudo informatizado.

F - É, exatamente. Nesses últimos dois anos assim a gente teve uma mudança radical. Tudo informatizado. Para você ter uma idéia, em setenta e nove éramos em mil e duzendos aproxima... aproximadamente. Hoje somos em seiscentos e poucos. Metade e continua produzindo a mesma coisa, talvez até mais. Então... E - É, mau para esse pessoal que sai, né?

F - É, com o neoliberalismo agora, né? eles vão buscar muitas idéias lá fora. Esse negócio da aldeia global. As refinarias lá fora, na Europa, na França, principalmente na França. Espanha eles estiveram também. Foram visitar e foram... e agora estão vindo com esse negócio de redução mesmo de custo. Então a redução é em cima do pessoal, através da informatização. Você (inint) os instrumentos, automatiza, né? Então a idéia é essa mesmo. Aí muda todo o conceito, né? porque ela, a Petrobrás tinha um conceito de estatal, tinha muito do objetivo social, né? Então era aquele cabidão mesmo, né? Você ia empregado, ia empregado. Hoje ela vai ter que se reestruturar, competir no mercado. Por exemplo, nós aqui em Araucária, uma refinaria de vinte e quatro mil metros cúbicos por dia, né? que processa, que refina, refinamento: uma empresa assim lá fora tem mais ou menos isso aí, seiscentos e poucos funcionários e não mil e duzentos, né? Então ela vai ter que se adequar porque com o tempo as refinarias vão ficar independentes, né? vão privatizar, vão ser privatizadas.

E - E eles já falam de privatização?

F - Já, eles estão falando de parceria, né? falando em parceiros lá. Na verdade, vai ser isso mesmo, uma privatização branca. $\mathrm{E}$ - É, uma privatização branca, bem isso.

F - Então é engraçado você num país de terceiro mundo assim e ver todo esse papo, todo esse discurso, né? da qualidade e de não sei quê e... menor preço, menos custo a qualquer preço, né? Investe no pessoal, mas investe menos, né? só aquele pessoal que realmente, que vai dar certo, que vai dar bom resultado, né? Porque antes... como eu te disse, né?, com esse lado social você tinha gente perdida lá dentro, né?, tudo que é tipo, né? E... enfim vai. Mas eu particularmente, quando eu comecei a fazer Letras foi justamente... procurei uma matéria da área humana, né? para 
dar uma contrabalançada, porque a área tecnológica assimé muito... E - É muito pesada? (PRCTB29 - Linhas 212 a 297)

Nesse texto, o falante não apresenta logo de início seu ponto de vista sobre a necessidade de modernização da empresa. Essa tese só é formulada após a apresentação do exemplo: Para você ter uma idéia, em setenta e nove éramos em mil e duzentos aproxima... aproximadamente. Hoje somos em seiscentos e poucos. Metade e continua produzindo a mesma coisa, talvez até mais. Esse exemplo é primeiramente relacionado com uma série de informações particulares que permitem contextualizá-lo e possibilitam ao falante passar da apresentação do exemplo à formulação de sua tese: as visitas dos dirigentes à França e à Espanha, a eleição das refinarias desses lugares como modelos, a comparação entre um conceito antigo e um novo de empresa estatal. A partir dessa contextualização, o falante apresenta sua tese: Hoje ela vai ter que se reestruturar, competir no mercado. Uma vez explicitada a tese, o mesmo exemplo apresentado antes é retomado, com o acréscimo dos índices de produtividade, mencionados de forma vaga anteriormente, e a indicação de uma característica que facilita sua aproximação com a tese formulada: a comparação entre os índices de produtividade atuais da refinaria e os índices observados nos modelos estrangeiros - Por exemplo, nós aqui em Araucária, uma refinaria de vinte e quatro mil metros cúbicos por dia, né? que processa, que refina, refinamento: uma empresa assim lá fora tem mais ou menos isso al, seiscentos $e$ poucos funcionários e não mil e duzentos, né? Essa retomada do mesmo exemplo, de forma mais detalhada e acrescida de sua comparação com o modelo, permite ao falante prosseguir sua argumentação com a retomada da tese apoiada em uma relação de causalidade. Ele não só reafirma a necessidade de reestruturação da estatal, como relaciona essa reestruturação a um projeto de privatização, apresentado com o estatuto de fato inevitável: Então ela vai ter que se adequar porque com o tempo as refinarias vão ficar independentes, né? Vão privatizar, vão ser privatizadas.

A argumentação do falante, neste caso, tem como acordo um conjunto de valores relacionados à modernização, produtividade e competitividade da empresa. Esses valores estão relacionados a um fato apresentado como irreversível: a globalização da economia. Notamos que ele constrói sua argumentação assumindo claramente o ponto de vista de um dirigente, co-responsável pelo desempenho da empresa. Quando fala da redução do quadro de funcionários observada na refinaria, ele se apresenta como administrador, preocupado em aumentar os índices de produtividade da empresa, não como um funcionário em defesa das condições de trabalho de seus pares: a Petrobrás tinha um conceito de estatal, tinha muito do objetivo social, né? Então era aquele cabidão mesmo, né? Você ia empregando, 
ia empregando.

O exame do conjunto de textos selecionados fornece uma resposta à questão proposta inicialmente: quais os recursos argumentativos mais prontamente acessíveis na argumentação mais elementar, produzida em instâncias privadas, sem planejamento prévio? Os textos indicam que os falantes buscam na sua experiência pessoal algum fato que possa se relacionar a sua opinião sobre o tema proposto, e certamente, sobre os temas que surgem naturalmente na conversação informal. Para os falantes, na conversa informal, a simples associação entre uma generalização e algum fato do seu conhecimento é suficiente para que se considere a tese suficientemente sustentada por evidências empíricas. Se, seguindo a esteira de Bakhtin, formos buscar a gênese do texto argumentativo em sua forma mais simples, o comentário informal emitido em uma instância privada, encontraremos um modelo que tem, essencialmente, dois componentes na sua organização argumentativa: a formulação de uma generalização e sua relação com um ou mais fatos particulares, que a exemplificam e ilustram.

\section{As marcas formais na articulação do texto argumentativo oral}

Outra forma de focalizamos os dados dos textos argumentativos analisados foi voltar nossa atenção para as marcas formais utilizadas na introdução da tese e na sua relação com os argumentos. Também em relação a esse aspecto, os textos apresentam a seleção de um conjunto restrito de marcas formais, as quais são usadas de forma recorrente nas várias entrevistas.

Uma primeira característica que pode ser apontada é o uso de marcadores conversacionais no momento da formulação inicial da tese:

Bom, eu acho que a propaganda... a mídia, ela faz a cabeça de muitas pessoas, $t a \mathfrak{a}$ ?

$E$, hoje em dia virou um... virou um... como é que posso te dizer, um... um... uma sexologia dentro de casa, né? que televisão hoje é só sexo.

$A h n$, fazer política em volta de uma mesa tomando cerveja é facílimo de se fazer, qualquer um faz.

Ao usar expressões como bom, tá, é no momento de apresentação da tese, 
os falantes indicam sua aceitação do tema proposto pelo entrevistador. Essas expressões funcionam como indicadores de tomada do turno e delimitadores do início da seqüência argumentativa. Claro que nem todos os textos selecionados têm sua delimitação inicial indicada pela presença desses elementos, mas os marcadores, quando aparecem, indicam a posse do turno e o desencadeamento de uma seqüência de enunciados, que contêm a apresentação de uma opinião e dos argumentos que a sustentam.

$\mathrm{Na}$ maioria dos casos, a formulação da tese vem logo no início do texto, introduzida ou não por um marcador conversacional. Uma vez apresentado o ponto de vista do falante sobre a questão que lhe foi proposta pelo entrevistador, a construção argumentativa tem como marca de continuidade o articulador porquê. Se o falante usa uma marca formal de articulação entre a tese e os argumentos, essa é, na imensa maioria dos casos, a forma escolhida.

Certamente, essa escolha está relacionada à forma como a argumentação é introduzida na entrevista oral. Como o tema é sempre apresentado pelo entrevistador, em geral sob a forma de uma pergunta, que, pelas normas conversacionais, obriga o falante a fornecer uma resposta, essa corresponde em geral à formulação da tese. Ora, faz parte do conhecimento discursivo dos falantes a necessidade de se apresentar justificativas para as opiniões formuladas. $O$ esquema de articulação entre tese $\mathrm{e}$ argumentos é aproximadamente o seguinte: o entrevistador propõe uma questão ( $O$ que você pensa de $x$ ?); o falante expõe e justifica seu ponto de vista (Acho que $y$ porque z). Às vezes aparecem outros articuladores com valor equivalente ao porque: que, em função de que:

E - O senhor acha que essas escolas que tem aqui, elas são suficientes ou precisaria ter mais, digamos assim?

F - Olha, eu acho que, principalmente pra segundo grau, precisaria mais uma aqui na nossa região, porque muita gente se desloca daqui. (PRCTB05 - Linhas 469 - 474)

Essa forma de marcar a articulação entre tese e argumentos distingue a oralidade da escrita, que se caracteriza pela ausência de marcas formais introdutoras tanto da tese quanto dos argumentos. Na escrita, os articuladores são utilizados para marcar relações lógico-semânticas entre as proposições. Na oralidade, têm muitas vezes uma função delimitadora, como é o caso do porquê empregado como marca de introdução dos argumentos. Os usos de por exemplo, por outro lado, portanto etc. na escrita indicam, em geral a relação que se estabelece entre as 
proposições na organização argumentativa. Nos textos orais analisados, os falantes assinalam, quase sempre mediante a presença do porquê, o momento em que passam da manifestação de seu ponto de vista sobre o tema proposto à apresentação de evidências para sustentá-lo.

Uma vez iniciada a apresentação de argumentos, as marcas formais utilizadas têm uma outra função, que podemos chamar, seguindo Tavares $(1999$, p. 10), de retroativo-propulsora, caracterizada como "a seqüenciação de informações pelo estabelecimento de uma ponte entre um enunciado passado e um futuro, servindo o primeiro de base para o que será dito no segundo."

A articulação entre argumentos é, assim, marcada pela presença de marcas formais que contribuem para a indicação de uma continuidade na apresentação de evidências. Entre os articuladores usados no português falado com esta finalidade estāo (d)aí, então, e, podendo ser encontrados usos combinados de (d)aí então, então (d)ai, e então, $e(d) a i$. Em trabalho de iniciação científica, realizado sob nossa orientação, Pretto (2000) demonstrou que, paralelamente ao processo de gramaticalização das formas (d)aí e então, notamos uma especialização de uso entre essas formas. $A \hat{i}$, usado originalmente como dêitico espacial, gramaticaliza-se como um relator retroativo-propulsor, empregado preferencialmente para a ligação entre proposições que estejam relacionadas por sua sequiência temporal. Assim, o uso de (d) ai aparece, nas entrevistas do Banco de Dados Varsul, especialmente na articulação dos textos narrativos. Essa mesma tendência foi documentada por Tavares (1999) na fala de Florianópolis.

Por outro lado o então, usado originalmente como advérbio com valor temporal, gramaticaliza-se como um articulador retroativo-propulsor também com uma especialização de uso, complementar aos usos de (d)aí. Então, no português falado, é usado atualmente para articular a continuidade entre proposições não relacionadas pela continuidade temporal. Assim, não é de se estranhar que a forma característica usada para indicar a sequiência de argumentos nos textos argumentativos analisados seja o uso do então:

E - Você, que trabalha em jardinagem, o pessoal destrói muito ainda as... as plantinhas, as gramas. A criançada não tem assim ainda essa consciência, por mais que apareça na televisão, que todo mundo fala? (ruído) (inint) e planta...

F - Não tem, porque você veja bem: as secretárias, vamos supor assim, o... a secretária, ou diretora, ou professora, vamos supor, de cada classe, que deveria orientar as crianças a zelar pelas plantas, elas não fazem. (est) Então daí, vamos supor, o jardineiro 
chega, planta, vai lá, poda, tá. Nós vamos de... cada trinta dias nós passamos em cada escola, né? Então dai você não... não tem como você orientar. E a direção do colégio não ajuda. A secretária, orientadora, que ganham pra isso não fazem. Então como é que você vai poder conservar um jardim? (est) Então tem às vezes que... em... em um ano você tem que reformular duas vezes um jardim. (PRCTB01 - Linhas 1468 - 1684)

Evidentemente, não temos nos textos unicamente o uso de então para fazer a ligação de partes de cada argumento entre si e para marcar a introdução de novos argumentos ao longo da construção textual. Mas ao examinarmos os textos fica evidente que essa é a marca usada de forma mais recorrente com essa função. As análises quantitativas feitas por Tavares (1999) e Pretto (2000) demonstram que nos textos argumentativos a função retroativo-propulsora é exercida majoritariamente pelo então, enquanto nos textos narrativos é o $(d)$ aí o articulador preferido para a mesma função.

Os textos mostram o uso de outros articuladores, que assinalam relações lógico-semânticas entre as proposições: porque, mas, quer dizer, por exemplo, tanto é que, em função de que etc. Mas o papel que esses elementos desempenham na construção textual é muito diferente daquele exercido pelo então (e minoritariamente pelo (d)aí). Esses articuladores, usados reiteradamente ao longo do texto oral assinalam-lhe o ritmo, têm uma função delimitadora, equivalente, de certa maneira à pontuação e paragrafação na escrita. Ao inserir um então no texto, o falante sinaliza sua progressão argumentativa.

A análise feita demonstrou que o texto argumentativo oral não planejado apresenta padrões bem definidos, tanto no que diz respeito a sua organização argumentativa quanto à articulação textual. Seria interessante, em trabalhos posteriores, fazer comparações entre as características observadas e as marcas correspondentes em textos escritos usados em instâncias diversas, para uma melhor compreensão do processo histórico de elaboração do gênero argumentativo. 


\section{RESUMO}

Procuramos, com o presente texto, apontar as características mais marcantes do texto argumentativo oral não planejado, observando-o sob dois ângulos. Primeiramente, buscamos identificar sua organização argumentativa e percebemos que ele se caracteriza, pela formulação de uma tese, na qual o falante faz, em geral uma generalização a propósito de alguma questão que o entrevistador lhe propõe. A seguir, expõe seus argumentos para a sustentação da tese. A argumentação encontrada se caracteriza, em geral, pela apresentação de casos particulares como evidências. Os argumentos se relacionam com a formulação da tese como exemplos, ou ilustrações. Na organização formal dos textos, em geral a tese é formulada logo no início do turno, tendo às vezes sua inserção marcada pelo uso de um marcador conversacional. A passagem da formulação da tese para a apresentação das evidências se đá, normalmente, pela presença do relator porque. Já a progressão ao longo da apresentação dos argumentos é marcada, tipicamente, pelo uso do articulador então.

Palavras-chave: Argumentação, coesão, oralidade.

\section{ABSTRACT}

In this study, we attempted to determine the most significant features of oral argumentative texts in light of two perspectives. First, we sought to identify their argumentative organization; we noted that it is characterized by the formulation of a thesis in which the speaker makes some generalization about something the interviewer has proposed. Following that, the speaker poses his/her arguments to support his/her thesis. The argumentation found features, in general, the presentation of particular cases as evidence. The arguments are related to the thesis formulation as examples or illustrations. Concerning the formal organization of the texts, the thesis is formulated at the onset of the turn-taking, having its insertion marked by the use of a conversational marker. The move from the thesis formulation to the presentation of evidence normally occurs with the use of porque. The progress along the argument presentation is typically marked by the use of então.

Key-words: Argumentation, cohesion, oral skills. 


\section{REFERÊNCIAS}

BAKHTIN, M. Estética da criação verbal. São Paulo: Martins Fontes, 1992.

BRANDÃO, H. N. (Org.). Gêneros do discurso na escola. São Paulo: Cortez, 2000.

COSTA, I. B.; GODOY, M. A. M. Um esboço de análise da argumentação na oralidade. Revista Letras, Curitiba, n. 48, p. 97-110, 1997.

GERALDI, J. W. Linguagem e ensino: exercícios de militância e divulgação. Campinas: Mercado de Letras, 1996.

KNIES, C. B.; COSTA, I. B. Banco de dados lingüísticos VARSUL - manual do usuário. UFRGS/ UFSC/UFPR/PUC-RS, 1996.

PÊCHEUX, M. Análise automática do discurso (AAD-69) In: GADET, F; HAK, T. Por uma análise automática do discurso. Campinas: Ed. da Unicamp, 1993.

PERELMAN, C. Retóricas. São Paulo: Martins Fontes, 1997.

PERELMAN, C.; OLBRECHTS-TYTECA, L. Tratado da argumentação. São Paulo: Martins Fontes, 1996.

PRETTO, J. O uso de articuladores retroativo-propulsores na fala da Regiäo Sul. 2000. Relatório de Iniciação Científica.

TAVARES, M. A. Um estudo variacionista de al, dai, então e e como conectores seqüenciadores retroativo-propulsores na fala de Florianópolis. Florianópolis, 1999. Dissertação (Mestrado) Universidade Federal de Santa Catarina.

VAN DIJK, T. A. Cognição, discurso e interạ̧ão. São Paulo: Contexto, 1992. 